\title{
Formation of Assimilating Surface Areas and Photosynthetic Potential of Various Assimilating Parts of Wheat Species under Drought Conditions
}

\author{
Tamraz H. Tamrazov, Javanshir M. Talai, Atif A. Zamanov \\ Azerbaijan Scientific-Research Husbandry Institute, Baku, Azerbaijan \\ Email: tamraz.tamrazov@mail.ru
}

Received 20 January 2016; accepted 19 April 2016; published 22 April 2016

Copyright (C) 2016 by authors and Scientific Research Publishing Inc.

This work is licensed under the Creative Commons Attribution International License (CC BY).

http://creativecommons.org/licenses/by/4.0/

(c) () D D Den Access

\begin{abstract}
Some of environmental factors (weather sharp fluctuations) may accrue stress within a few minutes, while others may not be long for this period of stress in this situation. It has formed stress in organisms, to eliminate the stress, there starts over various biochemical and physiological mechanisms for protection. Therefore, a large variety of plants to examine ways of increasing the resistance against stress factors have a scientific and practical importance. Thus, the primary processes of photosynthesis, based on the results of the study and its corresponding morphophysiological higher photochemical activity, has been found in a range of genotypes. Their leaves and plants assimilate the biological productivity of the intensity of the symptoms associated with the use of photosynthetic learned of the opportunity to create a new perspective varieties. This allows the research to prove the expansion of the electronic delivery of high-yielding genotypes and phosphorised chloroplast high speed, as well as the $\mathrm{pH}$ of thylacoid membranes are characterized by a great price, also photosynthetic electron transport, $\mathrm{CO}_{2}$ assimilation and it was approved to be the link between productivity.
\end{abstract}

\section{Keywords}

Assimilating Parts, Drought Conditions, Wheat Productivity, Bread Wheat, Physiological Mechanism

\section{Introduction}

Research on drought resistance of plants to the water system, in most cases, on the basis of skills and the ability

How to cite this paper: Tamrazov, T.H., Talai, J.M. and Zamanov, A.A. (2016) Formation of Assimilating Surface Areas and Photosynthetic Potential of Various Assimilating Parts of Wheat Species under Drought Conditions. American Journal of Plant Sciences, 7, 824-827. http://dx.doi.org/10.4236/ajps.2016.76077 
to adapt to natural conditions associated with heat and thirst, and in addition to the scientific interest in the nature of drought-tolerant plants, is of practical importance. Thus, it is connected directly to the final product demand for water from varied cultures in different period's ontogenesis. The decrease of level production of functional active for a long time associated with assimilating bodies.

Drought conditions in plants, especially those devoted to research in wheat productivity, the main focus of most research only involves the study of the effects of drought as a result of changes in physiological and biochemical indicators, drought-resistant plants are characterized on the basis of their rate. Stress factors (drought, salt, light, etc.) photosynthetic apparatus of bread and durum wheat genotypes impact of the structural and functional components.

It is known primarily as a result of crop planting photosynthetic assimilation is highly dependent on the size and the fact that it is functional for a long time. In this respect, the different varieties of drought conditions assimilate body's ontogenesis of these indicators to monitor the dynamics of the important practical significance [1]. In this regard, various types of drought conditions in the ontogeny of the dynamics of these indicators for monitoring assimilating body are an important practical significance [2].

In most cases, the research is based on the survival of the regime of drought and waters the plants, natural ability and the ability to adapt to the conditions associated with their thirst and heat [3]. Plant drought-resistant feature, in addition to the scientific interest has a great practical importance [4]. Thus, it is connected directly to the final product.

Cereal demand for water has been different in different periods of ontogenesis. The decrease of level production of functional active for a long time associated with assimilating bodies [5].

Drought conditions in plants, especially wheat productivity in many scientific studies have explored the effects of drought as a result of not only focuses on the study of physiological and biochemical indices of change, drought-resistant plants, based on their fixed rate.

In some studies, the effect of drought on productivity is measured only in the final result of the product. Thus, the physiological process in which the leading role of this or that productivity remains unclear [6].

Some authors have shown that, in times of drought-resistant plants, photosynthetic potential of drought-resistant plants that do not remain at a relatively high level [7]. Some authors have shown that, during periods of drought photosynthetic capacity of drought-resistant plants, plants that are not resistant to remain relatively high levels [8].

\section{Objects and Methods}

At the same time in scientific literature the information about of the integral the effects of drought to photosynthesis is almost is not enough can say that is not enough.

The special density of leaf surface and optimal sizes of assimilation surfaces, the amount of photosynthetic pigments, photosynthetic potential (PP), the economic efficiency of photosynthesis and net productivity and others are considered to be the factors that determine the productivity of wheat [9].

As it is known, the drought is affecting the development process; it also leads to a reduction of photosynthetic capacity and assimilation surface of leaves. Therefore, reductions in the size of the surface of the leaves in times of drought, one of the main causes of changes in productivity from year to year. Drought in the South and East regions limits the growth of the leaf surface during vegetation and it rarely has here optimal sizes to absorb the photosynthetic active radiation (FAR) falling to the planting. [10]

Plant productivity is determined by the assimilation of the surface dimensions and continuity of its surface. Therefore, the optimal size of leaf surface only is accessed more quickly, but also important to the maintenance of its long-acting. The leaf surface which equal to 40 - 50 thousand $\mathrm{m}^{2} /$ ha is considered an optimal. Field experiments were conducted in other crops, including wheat, causing some believe that the optimization of culture conditions and 50 - 70 min yield $\mathrm{m}^{2} /$ ha higher in the leaf surface [11].

Excessive increase in the ratio of leaf surface and biological farming does not lead to an increase in the product. The rise of the optimal size of the surface of the leaves worsens light regime inside the crop and eventually reduces the possibility of a lower level assimilation sharply.

\section{Results}

For the study of given were taken parameters of different varieties of durum and bread wheat (Garagilchiq-2, 
Baraketli-95, Giymatli 2/17 and Girmizigul-1).

The results of measuring the surface area of leaves and other organs were analyzed. As it is seen from data in early ontogenesis Garagilchig-2 and Baraketli-95 leaves, leaf area control and practicing increases suddenly, at the second decade of April reaching to maximum at the end of deduction the pipe from the phase the pipe of clone Garagilchig-2-62 and 46 thousand $\mathrm{h} \cdot \mathrm{m}^{2} / \mathrm{ha}$, and varieties of Baraketli-95 is -56 and 48 thousand $\mathrm{m}^{2} / \mathrm{ha}$, difference between the variants is $26 \%$ and $15 \%$.

Since the decline of the leaf surface and in late June and first half of the control and experimental variants Garagilchig-2 in accordance with the clone 38 and $18 \mathrm{~m}^{2} / \mathrm{ha}$, Baraketli- 95 cultivar 35 and $22 \mathrm{th} \cdot \mathrm{m}^{2} / \mathrm{ha}$ falls to $53 \%$ and $38 \%$ respectively.

Bread wheat is valued in the early ontogeny securities Giymatli-2 /17 and Girmizigul-1 the clone 55 and 41th. $\mathrm{m}^{2} / \mathrm{ha}, 49$, and $43 \mathrm{th} \cdot \mathrm{m}^{2} / \mathrm{ha}$ of difference between the embodiments is $16 \%$ and $13 \%$. At the end of the first decade the ontogenesis of June are 36 and 25 thousand $h \cdot \mathrm{m}^{2} / \mathrm{ha}$ Giymatli-2/17 clone, and Girmizigul-1 27 and 24 th. $\mathrm{m}^{2} /$ ha variety. Differences between $30 \%$ and $11 \%$ are respectively. Accordingly, the effects of drought and leaf ontogeny in aging leaf surface area reduction by more than half.

The housing of the control and experimental variants increase surface phase continues until the formation of corns and a maximum reach of Garagilchig-2, 70 and $55 \mathrm{th} \cdot \mathrm{m}^{2} /$ ha of various, Baraketli-95 varieties 79 and 60 th. $\mathrm{m}^{2} / \mathrm{ha}, 21 \%$ and $24 \%$ of the difference between the options, at the end of ontogeny genus Garagilchig-2, 24\% and $17 \%$ for Baraketli-95.

Giymatli-2/17 and the power of the grapes Girmizigul-1 shows that the dynamics of change, an increase in the rate of phase leaves a lot of pipes. As you can see, this is due to the fact that the pipe from the development stage is complete after all the leaves, stem continue to evolve. The maximum area of enclosures, as well as the other sort, is observed during the formation of corns. Equity is the difference between the ontogenesis Giymatli2/17 varieties of options; according to the strength of 32\%, and 20\% is sort Girmizigul-1.

Experience all of the surface area of the spike with a choice of options to control vine is growing more rapidly than the middle of May, after the formation of the spike reaches maximum. Garagilchig-2, 28.7 and 19.6 th $\cdot \mathrm{m}^{2} /$ ha in accordance with the sort Baraketli-95 cultivar, 25.6 and $18.7 \mathrm{th} \cdot \mathrm{m}^{2} /$ ha is the difference between the variants were $32 \%$ and $24 \%$.

Varieties of bread wheat, the maximum point of the securities in accordance with Giymatli-2/17 and Girmizigul-1 are 22.3: 21.2 and $18.216 .4 \mathrm{th} \cdot \mathrm{m}^{2} / \mathrm{ha}$. The difference between the variants is $5 \%$ and $11 \%$. It allows you to record up to that comparison, the surface area of leaves, stem and spike as a result of the impact of drought is more surface area. The optimal size of the leaf surface and to measure the photosynthetic potential of leaves of different DLS (PP) and the leaf surface itself, as well as the leaves are used as a connecting DLS.

Different periods of vegetation photosynthetic capacity of leaves and other organs prices assimilation 2 period: As you can see from the results studied. Researching to blossom in later periods up to and during the period blooming leaves varieties durum wheat Garagilchig-2 and Baraketli-95 control of PP version $2.67 ; 3.37 \mathrm{th} \cdot \mathrm{m}^{2} / \mathrm{ha}$ day, the 2.31 version of the experience; $2.76 \mathrm{th} \cdot \mathrm{m}^{2} /$ ha days. Assimilating other control bodies in accordance with the version $2.20 ; 2.67 \mathrm{th} \cdot \mathrm{m}^{2} /$ ha day, practice version $2.01 ; 2.22 \mathrm{th} \cdot \mathrm{m}^{2} /$ ha days.

Varieties of wheat breads in the control of the security options are Giymatli-2/17 and Girmizigul-1 3.28; 1.85 $\mathrm{th} \cdot \mathrm{m}^{2} /$ ha day, practice version $2.50 ; 1.53 \mathrm{th} \cdot \mathrm{m}^{2} /$ ha days. Assimilating other control bodies in accordance with the version $3.12 ; 1.68 \mathrm{th} \cdot \mathrm{m}^{2} /$ ha day, practice version $2.46 ; 1.26$ thousand. $\mathrm{m}^{2} /$ ha days.

Varieties of durum wheat in the next version of the PP control blooming $1.45 ; 0.94 \mathrm{th} \cdot \mathrm{m}^{2} /$ ha day experience version $0.84 ; 0.62 \mathrm{th} \cdot \mathrm{m}^{2} /$ ha day, according to other organs assimilate $2.52 ; 1.86$ and $2.07 ; 1.42 \mathrm{~m}^{2} /$ ha days.

\section{Conclusions}

Indeed, according to the phases of the leaves and leaf growth dynamics of PP show that the maximum price Garagilchig-2 and Baraketli-95 varieties in the same phases are observed in these figures. Assimilating different periods of vegetation leaves and other organs indicate that the price of PP, PP leaves and other organs of assimilate Garagilchig-2 and Girmizigul-1 than varieties of grapes are Baraketli-95 and Giymatli-2/17 wheat. As it seen from these figures tall and broad-leaved vine leafy areas are increasing due to excessiveness. Photosynthetic capacity is compatible with the maximum price, the maximum price of the ontogenesis of leaves.

The impact results to the drought, as well as to all the major integrated indicators of photosynthetic activity and leaf surface bigness, dry biomass accumulation, pigments content, photosynthetic capacity, farming efficiency determining the product of photosynthesis and clean productivity were achieved. 
Thus, the results of the study show that the ontogenesis and photosynthetic capacity of the leaf surface area of organs and other assimilating dynamic nature of the genetic characteristics of plants, not just the development phase, but also environment favorable factors, as well as on the impact of drought.

\section{Acknowledgements}

I ask you to print prepared articles on the basis of the results of the scientific research work in the field of plant physiology in the Azerbaijan Republic in your leading scientific journal.

The article is about changing the dynamics of physiological parameters from the effects of drought of different wheat genotypes. It is very important for me to print the article. I would ask you to consider these things. I thank you in advance for publication of the article.

\section{References}

[1] Aliyeв, J.A. (2000) Physiological Leaves of What Breeding Tolerant to Water Stress Wheat in Global Environment. Proceedings of the 6th International Wheat Conference, Budapest, 5-9 June 2000, 693-698.

[2] Aliyev, J.A. and Kazibekova, E.G. (1998) Importence of Photosynthetic Character of Productivity and Its Using Inbreeding Ideal Wheat. Photosynthesis and Production Processes, 237-242.

[3] Aliyev, J.A. and Kazibekova, E.G. (1979) Features of Photosynthetic Intensity of the Extensive and Intensive Wheat Varieties. Publisher Science, Az. SSR Academy, Ser. Biol. Science, No. 3, 10-14.

[4] Genkel, P.A. (1978) The Modern Condition of the Droughtresistance of Plant. 25, 889.

[5] Brooks, T.J., Wall, G.W., Pinter Jr., P.J., Kimball, B.A., La Morte, R.L., Leavitt, S.W., Matthias, A.D., Adamsen, F.J., Hunsaker, D.J. and Webber, A.N. (2000) Acclimation Response of Spring Wheat in a Free-Air CO Enrichment (FACE) Atmosphere with Variable Soil Nitrogen Regimes. 3. Canopy Architecture and Gas Exchange. Photosynthesis Research, 66, 97-108.

[6] Magarramov, M.J. (1995) Gas Exchange $\mathrm{CO}_{2}$ Genotypes of the Different Wheat Yield in Relation to Drought Resistance. Abstract. Diss. on the Competition. Cand. Biol. Science, Baku, 24.

[7] Medvedev, A.M. and Razumov, V.I. (1986) Comparative Study of the Leaf Area and Photosynthetic Potential of the Different Winter Wheat Varieties in Relation to Drought Resistance. Scientific Technology of Biol., 164, 13-15.

[8] Kuzmin, M.S. (1986) Formation of Assimilation Surface and Productivity of Photosynthesis in Soybean Plants. Biology, Genetics and Breeding of Soybeans, Siberia, 125-134.

[9] Nikolaev, V.D. and Rusakov, V.V. (1986) Photosynthetic Activity and Soybean Productivity Depending on Mineral Nutrition Conditions. Biol. Selek. and Genet. Soya. Novosibirsk, 20-33.

[10] Tambussi, E.A. (2005) Ear of Durum Wheat under Water Stress: Water Relations and Photosynthetic Metabolism. In: Tambussi, E.A., Nogues, S. and Araus, J.L., Eds., Planta, 1-25.

[11] Talai, J.M. (1995) Morphophysiological Characteristics of the Drought Resistance of the Economically Valuable Genotypes. Abstract. Diss. on Soisk. Cand. Biol. Sciences. Baku, 23. 